\title{
Investigation of production forecast biases of simulation models in a benchmark case
}

\author{
Vinicius Eduardo Botechia*, Ana Teresa Ferreira da Silva Gaspar, Guilherme Daniel Avansi, Alessandra Davolio, \\ and Denis José Schiozer \\ University of Campinas, PO Box 6052, 13.083-970 Campinas, Saoaulo - Brazil
}

Received: 27 February 2018 / Accepted: 23 April 2018

\begin{abstract}
Reservoir management decisions are often based on simulation models and probabilistic approaches. Thus, the response of the model must be sufficiently accurate to base sound decisions on and fast enough to be practical for methodologies requiring many simulation runs. However, simulation models often forecast production rates different to real production rates for various reasons. Two possible causes of these deviations are (1) upscaling (a technique to reduce the computational time of simulation models by reducing the number of grid blocks) and (2) uncertainties (the values established to attributes are different from real values caused by lack of knowledge of real reservoir). Morosov and Schiozer (2016) applied a closed-loop technique in a benchmark case where decisions taken using the simulation models are applied to a reference case. The optimized production strategy, using simulations models, increased the expected monetary value of the project by about $29 \%$, but the Net Present Value (NPV), calculated using a reference case, decreased by $2 \%$. The real NPV was outside the expected range and revealed that the set of models did not fully represent the real field, even for high-quality history-matched models. The objective of this study is to identify the causes of these discrepancies. To reach this goal, we investigate and analyze both the impact of the upscaling and the uncertainty on production and economic indicators. We use a set of representative models of benchmark UNISIM-I (Avansi and Schiozer, 2015) to consider the effects of uncertainty and upscaling. Our main concern was the uncertainties in the distribution of petrophysical properties that strongly influence the productivity and injectivity of wells, noted by Morosov and Schiozer (2016) as being the main cause for differences among models. Furthermore, to verify the isolated effects of the possible causes of deviation, we use a single model to show only the effects of upscaling, and another set of models showing only the uncertainty. The results showed that the impact of the uncertainties was higher than the upscaling for the studied case. The upscaling generated an optimistic bias for production and economic indicators, but well-correlated with the reference case. The uncertainties significantly affected the production forecasts for this study. This happened because the response of the wells is highly dependent on the petrophysical properties of the model, which varies widely between the different models representing uncertainties and was not adequately depicted by the representative models.
\end{abstract}

\section{Introduction}

A principal objective of oil companies is to maximize the economic performance of the field. Efficient management is fundamental to achieve this goal. Field management is complex with many decisions involving high investments and many uncertainties.

Decisions in petroleum industry are often made based on production forecasts. However, these predictions are

\footnotetext{
* Corresponding author: botechia@cepetro.unicamp.br
}

subject to several sources of errors. Begg and Bratvold (2008) investigated the main sources of prediction errors and their impact on the decision making. The authors listed some of the main sources of errors as follows: uncertainty, biased inputs, mistakes (logic, analysis, data entry, computation, or limitations of measurement devices), use of models and variation in the project execution (changes in decisions).

The optimistic bias of predictions has been reported in the literature using different terms: post-decision surprise (Harrison and March, 1984), the optimizer's curse (Smith and Winkler, 2006; Schuyler and Nieman, 2007), and inevitable disappointment (Chen and Dyer, 2009). 
Usually, production prediction tasks, economic analyses, and other oil field management activities involve numerical simulation. Thus, reliable simulation models are necessary to accurately predict field performance. One of the key points concerning model reliability is the grid-cell size, meaning that a high resolution grid is desirable to incorporate detailed data and properly represent heterogeneities and the flow behavior of fields.

However, fine-scale models may increase levels of computational effort so much that important petroleum reservoir activities are unfeasible, mainly those that are usually addressed using probabilistic approaches and requiring many simulation runs. Some examples of these activities are: production strategy optimization (AlHarthy, 2010; Korounis et al., 2014; Oliveira et al., 2015; Gaspar et al., 2016a), decision analysis procedures (Fletcher and Davis, 2002; Pattillo et al., 2003; Cunha, 2007; Schiozer et al., 2015; Ani et al., 2016), and Value Of Information (VOI) estimates (Gerhardt and Haldorsen, 1989; Coopersmith and Cunningham, 2002; Bratvold et al., 2009; Keisler et al., 2014; Santos et al., 2017).

To enable production strategy optimizations, decision analyses, and VOI estimates, fast models are created to reduce the computational time. These fast models can be created, for instance, through upscaling, which takes refined geostatistical models to make coarser reservoir simulation models by applying averaging or flow-based techniques (Gorell and Bassett, 2001). However, the inevitable loss of information on these models (Maschio and Schiozer, 2003) means that the accuracy of the results diminishes because of simplifications made on spatial heterogeneity variation (Gorell and Bassett, 2001; Bordeaux-Rego et al., 2016).

Romeu and Noetinger (1995) presented one of the first studies regarding the intrinsic bias of simulations. The authors conducted an analytical and numerical investigation of the finite difference computation of the equivalent conductivity of heterogeneous porous media. They also proposed a method to correct the bias caused by unrefined blocks in this case.

Several authors attempted to improve upscaling techniques. Preux (2014) and Preux et al. (2016) presented methodologies and indicators to evaluate the most appropriate upscaling technique for a determined study case, also assessing the quality of the upscaled reservoir model.

Furthermore, there is a strong interaction between the heterogeneity and an unstable character of the fluid flow displacement. This coupling may change the form of the large-scale equations and should be accounted for in the upscaling processes (Artus and Noetinger, 2004).

Many papers addressed two-phase flow upscaling, taking into account the interaction between unstable displacement (or viscous fingering) and heterogeneities in the upscaling process (Noetinger et al., 2004; Noetinger et al., 2005; Luo et al., 2016).

Schiozer et al. (2015) presented a closed-loop reservoir management methodology in which the first steps treat the construction and calibration of simulation models. The authors state that, to accurately quantify risk, it is necessary to trust in the response of the model for each created scenario. This means that the model must be calibrated to produce an effective response and be robust enough to avoid bias.

Besides the upscaling, another source of error in simulation and management is quantifying and mitigating uncertainty. Begg et al. (2002) demonstrated that, generally, oil companies underperform because of poor investment decisions, which is in turn associated to inaccurate evaluation of the economic impact of uncertainties. Bickel and Bratvold (2008) stated that while quantifying uncertainty has improved in the last decade, this has not yet produced a similar improvement in decision making.

In fact, this paper evolved from other model-based management researches that used the same benchmark case. Morosov and Schiozer (2016), for instance, applied a closed-loop technique in this benchmark consisting of three main steps: data acquisition, history matching and production strategy optimization. These steps were repeated in several cycles using simulation models. After that procedure, the expected monetary value obtained with the final strategy increased about $29 \%$ in relation to the base case. However, the same strategy was applied to a reference case (considered as the real response) and the real NPV actually decreased by $2 \%$, falling below the expected range and revealing that the set of models did not fully represent the real field. The authors quote that the possible causes of this misrepresentation are: lack of geostatistical variability, history-matching convergence to incorrect parameters and the upscaling process.

The objective of this work is to investigate the causes of errors detected in the simulation models in the work of Morosov and Schiozer (2016) by quantifying the effects of upscaling and uncertainties on production and economic indicators and how they impact model-based decisions.

To represent a real reservoir we use a synthetic finescale model as a reference, and a set of simulation models derived from the reference case, incorporating both effects of upscaling and uncertainties. We also use a simulation model showing only the effects of upscaling and another set of models showing only the effects of uncertainties (since they have the same scale as the reference case). All the models are part of the UNISIM-I benchmark case (Avansi and Schiozer, 2015). More details about this benchmark are presented in next section.

In the following sections, we describe the cases used in this work (2), the methodology (3), the results and discussion (4), followed by the main conclusions (5).

\section{Reference case and simulation models}

\subsection{UNISIM-I-R (Reference case)}

The benchmark UNISIM-I (Avansi and Schiozer, 2015) was created to be used in numerical simulation and management integrated studies of petroleum reservoirs, allowing methodologies to be tested and compared by different research groups. This constructed benchmark was intended to substitute a real reservoir for a reference model with known properties in a high-resolution grid. 


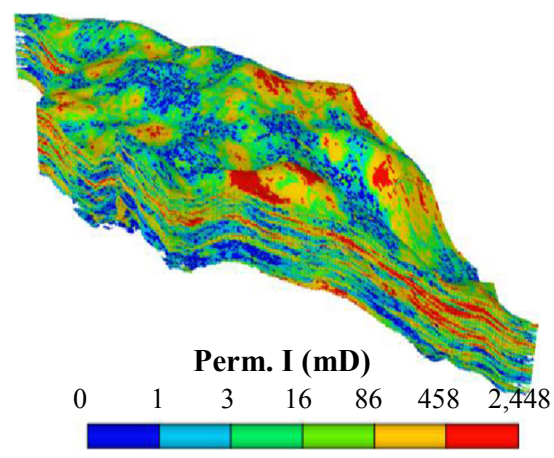

Fig. 1. Benchmark UNISIM-I-R: 3D view of horizontal permeability in logarithmic scale.

Table 1. UNISIM-I-R parameters.

\begin{tabular}{ll}
\hline \multicolumn{1}{c}{ Parameter } & \multicolumn{1}{c}{ Value } \\
\hline Permeability $(\mathrm{mD})$ & $0.1-2448($ av. $\sim 150)$ \\
Porosity & $0.01-0.32($ av. $\sim 0.17)$ \\
Depth $(\mathrm{m})$ & $2870-3349($ av. $\sim 3078)$ \\
Oil viscosity $(\mathrm{cP})$ & $1.08-1.20($ av. $\sim 1.10)$ \\
Initial pressure $\left(\mathrm{kg} / \mathrm{cm}^{2}\right)$ & $318-357($ av. $\sim 332)$ \\
\hline
\end{tabular}

UNISIM-I-R was built in a high-resolution geocellular model, with public data of the Namorado Field, Campos Basin, Brazil. The geological model has a high level of detail to ensure reliability. The model has a corner-point grid, with 11976588 blocks $(326 \times 234 \times 157)$, with 3367901 active blocks. Each grid cell has measures $25 \mathrm{~m} \times 25 \mathrm{~m} \times$ $1 \mathrm{~m}$. The total simulation time is about $70 \mathrm{~h}$ in a cluster of 12 processors. For ease of reading, this model is referred to only as $\mathbf{R}-\mathbf{f}$ in the remainder of the text.

Figure 1 shows the horizontal permeability map in logarithmic scale for UNISIM-I-R and Table 1 shows selected field parameters.

\subsection{UNISIM-I-M (Set of simulation models for management studies)}

The benchmark UNISIM-I-M (Gaspar et al., 2016b) is a set of simulation models designed for studies on the management phase, i.e., the period after strategy implementation, when most of the infrastructure has already been defined. The simulation models are based on information from the reference model UNISIM-I-R.

The UNISIM-I-M model has a coarser grid than the reference case, with 93960 blocks $(81 \times 58 \times 20)$ measuring $100 \mathrm{~m} \times 100 \mathrm{~m} \times 8 \mathrm{~m}$. The total simulation time is about 7 min in a cluster of 4 processors.

The initial production strategy is a water-flooding project with 25 wells (14 producers and 11 injectors) with 7 years of production history data.

The set of models was built considering the following uncertainties: structural models, Pressure, Volume, and Temperature dependencies (PVT), Oil-Water Contact (OWC), water relative permeability, rock compressibility, and 500 geo-realizations with petrophysical characteristics related to facies, Net-To-Gross (NTG) ratio, porosity, horizontal and vertical permeabilities. Combining these uncertainties, 2000 possible scenarios were generated, and then a probabilistic history-matching process was applied to reduce the number of scenarios, resulting in 48 scenarios (simulation models). This set of scenarios, combining all uncertainties and geo-realizations, honoring the history data in previously defined confidence interval compose UNISIMI-M. Figure 2 shows the 3D view of one realization of UNISIM-I-M, with the location of producers (Fig. 2a) and injectors (Fig. 2b).

\subsection{Representative models}

Representative Models (RM) are widely used to reduce the number of models for optimization purposes (Schiozer et al., 2004; Costa et al., 2008; Marques et al., 2013; Sarma et al., 2013; Shirangi and Durlofsky, 2015). The RM represent the variability of the uncertainties within a small number of models. Thus, all RM can be optimized to have different project options, each one representing a different scenario. For UNISIM-I-M, 12 RM were selected, according to the procedure suggested by Meira et al. (2016), in which the selected models present significant variations in several indicators such as Net Present Value (NPV), cumulative oil and water produced, and oil recovery factor. In the following sections, these models are referred as RM-c.

\subsection{Upscaling in the reference case and fine-scale representative models}

To exclude the effects of uncertainties and analyze only the impact of the upscaling, we generated an upscaled model directly from the reference case, referred to in this work as model R-c. This model has the same grid scale as the UNISIM-I-M models. Moreover, to exclude the upscaling effect and verify only the impact of the uncertainties, we used 12 fine-scale models, which consist of the same 12 geostatistical realizations that generated the $12 \mathrm{RM}$, but with the same grid as the reference case. We refer to them in this text as RM-f.

Figure 3 shows the schematic procedure to generate the UNISIM-I models, starting with the reference case, the generation of uncertainties, upscaling, history matching and the selection of representative models. The boxes highlighted in blue show the different models addressed in this work: R-f (reference case), R-c (only upscaling effect), RM-f (only uncertainty effects), and RM-c (both upscaling and uncertainty effects). Table 2 summarizes all the models used in this work.

\section{Methodology}

The main task in this paper is to compare the behavior of production strategies in different simulation models, observing the discrepancies in relation to the real response (reference case). In this context, the methodology consists of the following steps:

- definition of production strategies for the representative models; 


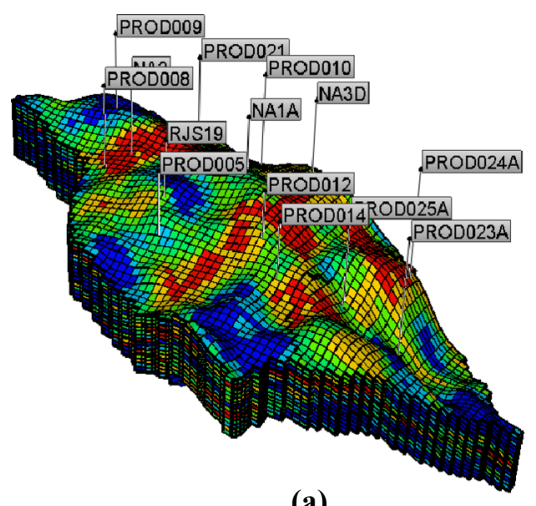

(a)

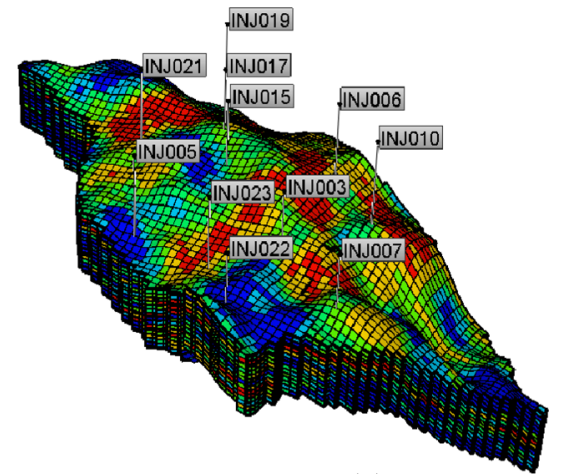

(b)

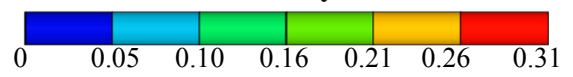

Fig. 2. Porosity map of one realization of UNISIM-I-M, with the location of a) producers; b) injectors.
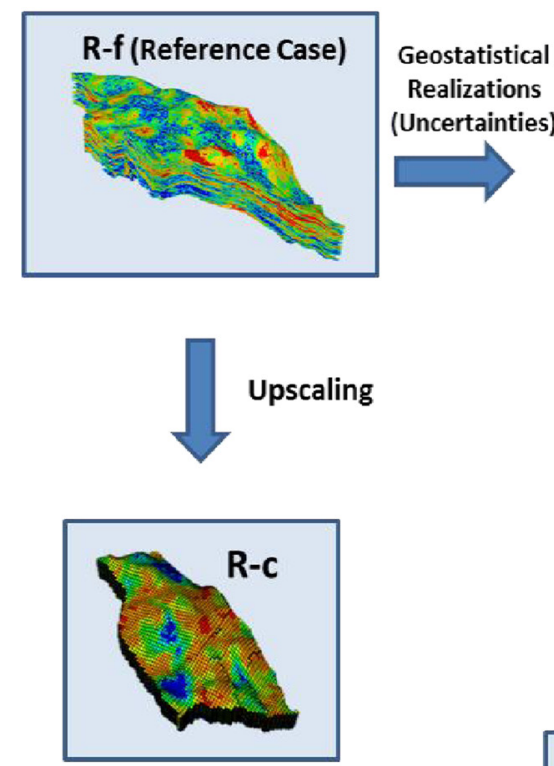
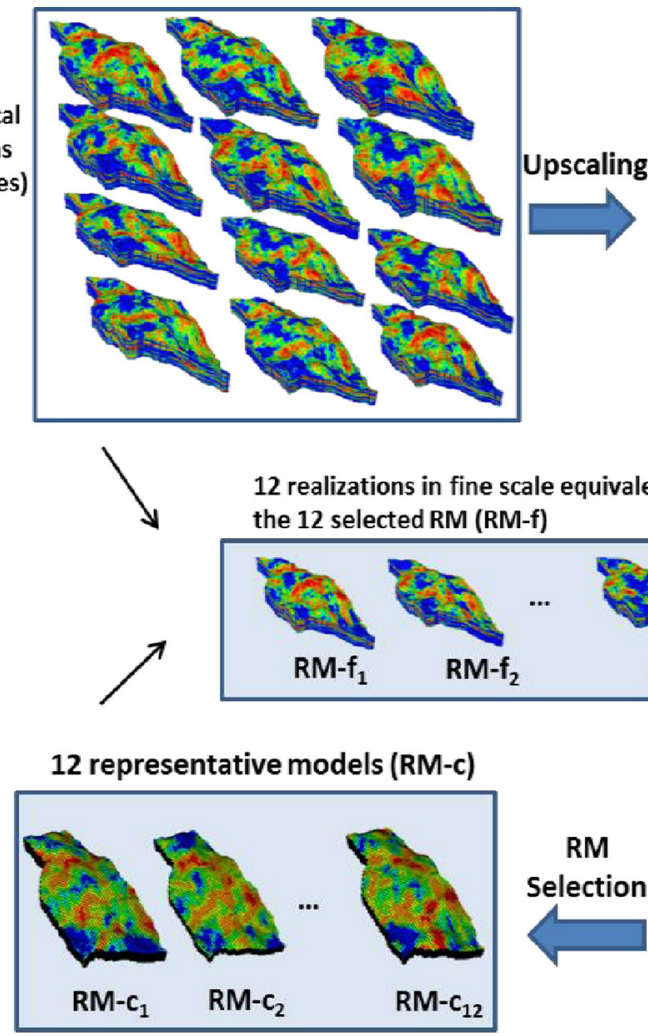

scale (a)

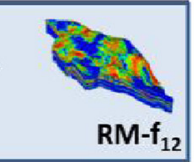

2000 simulation models
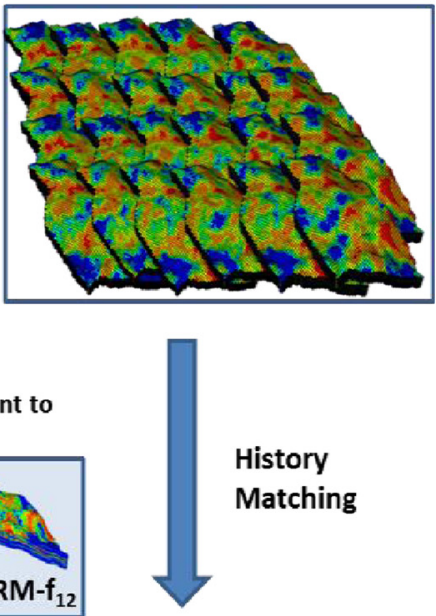

History

Matching

Fig. 3. Schematic of UNISIM-I-M model generation. The highlighted blue boxes represent the models used in this work.

- simulation of the production strategies in the following models (besides the RM-c):

- R-f (reference case, to verify the real response of the strategies);

- RM-c (isolated effect of the upscaling);

- RM-f (isolated effect of the uncertainties);

- NPV calculation for each strategy, for each aforementioned model;

- analysis of the results.
The first step aims to optimize the production strategy for each representative model. As this work focuses on a field in the management phase, the initial production strategy is not altered, as it has already been implemented. Wells are placed after the historical period, in undrained areas, to increase the economic return, measured by NPV. We optimized all 12 RM-c and also the model R-c, totaling 13 different strategies. The 
Table 2. Summary of the models used in this work.

\begin{tabular}{lll}
\hline Model & \multicolumn{1}{c}{ Description } & $\begin{array}{l}\text { Quantity } \\
\text { of models }\end{array}$ \\
\hline R-f & Reference case (fine-scale grid) & 1 \\
R-c & Upscaling in reference case (coarse grid) & 1 \\
RM-f & Representative models in fine-scale & 12 \\
RM-c & Representative models in coarse scale & 12 \\
\hline
\end{tabular}

Table 3. NTG cut-off based on the interval facies.

\begin{tabular}{ll}
\hline Facies & NTG \\
\hline 0 & 1.0 \\
1 & 0.8 \\
2 & 0.6 \\
3 & 0.0 \\
\hline
\end{tabular}

increment in economic return is measured by the difference between the NPV of the optimized strategy and the base strategy for each RM.

\section{Application}

\subsection{Geostatistical realizations}

Facies modeling was defined using a Sequential Indicator Simulation (SIS) with vertical trend (Ravenne et al., 2002). In the general context, applying SIS provides 3D realistic images of the reservoir heterogeneities and is useful for controlling fluid flow and assessing final uncertainties in production (Seifert and Jensen, 1999).

Petrophysical modeling of porosity was defined using a 3D stochastic modeling, SGS, to perform the petrophysical modeling of porosity; combining well logs, distribution values for omnidirectional variograms and $3 \mathrm{D}$ facies model to control and condition the porosity distribution (Dubrule, 1998; Kelkar and Perez, 2002). This is a kriging-based method in which unsampled locations are visited in a random order until all are visited. Porosity was then simulated, reproducing per-facies distribution as derived from the blocked well data.

For our 3D models, we defined the Net-To-Gross (NTG) cut-off based on the interval facies as illustrated in Table 3. We also assumed a linear dependence of porosity and log-permeability in the core description data (Avansi and Schiozer, 2015). So, we use a linear regression to get an equation to represent the log-permeability distribution as a function of porosity for the entire reservoir model.

More information about the simulation model, geostatistical realizations and uncertainties can be seen in Avansi and Schiozer (2015) and Schiozer et al. (2017).

\subsection{Upscaling}

Porosity is upscaled by simply using a volume-weighted arithmetic averaging method and we choose to weight it by

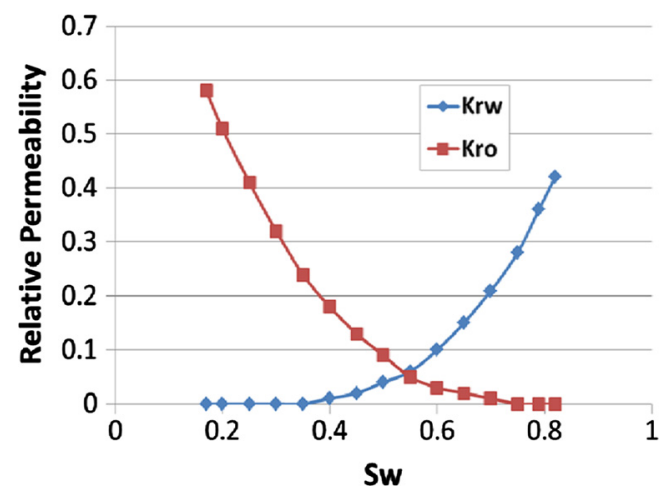

Fig. 4. Reference case relative permeabilities.

NTG. The idea is to ensure that the hydrocarbon pore volume remains constant when upscaling (additive property characteristics).

Permeability is upscaled using a flow-based upscaling technique, which produces effective permeability to replicate the fine-scale behavior (before the upscaling) in overall flow rate by using a single-phase pressure solver, FLOWSIM (Deutsch, 1989). When an isotropic permeability is upscaled, the case of this work, the effective results become anisotropic; three effective permeabilities in all directions ( $\mathrm{i}, \mathrm{j}$, and $\mathrm{k}$ ) are then obtained for the upscaled reservoir (SIM model).

NTG is upscaled using a volume-weighted arithmetic averaging with no weighting properties. NTG is also an additive property and it is directly related to maintaining constant the hydrocarbon volume during the application.

\subsection{Models data}

Figure 4 shows the relative permeability curve of the reference case, and Table 4 presents PVT data.

\subsection{Economic parameters}

Table 5 shows the economic parameters for NPV calculation, based on Gaspar et al. (2015).

\section{Results}

For each strategy, we calculated the NPV for the following situations: (a) the strategy applied to the representative model (NPV $\mathrm{RM}_{\mathrm{C}-\mathrm{c}}$ ), (b) the strategy applied to the reference case $\left(\mathrm{NPV}_{\mathrm{R}-\mathrm{f}}\right)$, (c) the strategy applied to model R-c $\left(\mathrm{NPV}_{\mathrm{R}-\mathrm{c}}\right)$, and $(\mathrm{d})$ the strategy applied to RM-f $\left(\mathrm{NPV}_{\mathrm{RM}-\mathrm{f}}\right)$.

Figure 5 shows the NPV values obtained for each strategy. Note the visible optimistic bias generated by the upscaling. For each strategy, the highest NPV is obtained for the case where only the upscaling effect is considered (green columns). Similarly, note that the uncertainties tend towards a pessimistic bias (red columns). The purple columns are the results from the reference case. In Figure 6, we observe a similar behavior for the produced cumulative oil produced $(\mathrm{Np})$. 
Table 4. PVT data.

\begin{tabular}{lllllll}
\hline $\mathrm{p}$ & Rs & Bo & Bg & viso & visg & co \\
\hline 35 & 32 & 1.20 & $3.46 \mathrm{E}-02$ & 2.05 & 0.0109 & $1.62 \mathrm{E}-04$ \\
42 & 35 & 1.20 & $2.91 \mathrm{E}-02$ & 1.99 & 0.0113 & $1.62 \mathrm{E}-04$ \\
49 & 38 & 1.21 & $2.45 \mathrm{E}-02$ & 1.91 & 0.0117 & $1.62 \mathrm{E}-04$ \\
60 & 43 & 1.23 & $1.99 \mathrm{E}-02$ & 1.81 & 0.0123 & $1.62 \mathrm{E}-04$ \\
69 & 47 & 1.24 & $1.72 \mathrm{E}-02$ & 1.73 & 0.0128 & $1.62 \mathrm{E}-04$ \\
81 & 53 & 1.25 & $1.44 \mathrm{E}-02$ & 1.62 & 0.0134 & $1.62 \mathrm{E}-04$ \\
94 & 59 & 1.27 & $1.23 \mathrm{E}-02$ & 1.52 & 0.0142 & $1.62 \mathrm{E}-04$ \\
106 & 64 & 1.28 & $1.08 \mathrm{E}-02$ & 1.43 & 0.0148 & $1.62 \mathrm{E}-04$ \\
122 & 72 & 1.30 & $9.30 \mathrm{E}-03$ & 1.32 & 0.0157 & $1.62 \mathrm{E}-04$ \\
134 & 77 & 1.32 & $8.40 \mathrm{E}-03$ & 1.25 & 0.0164 & $1.62 \mathrm{E}-04$ \\
148 & 84 & 1.33 & $7.60 \mathrm{E}-03$ & 1.17 & 0.0172 & $1.62 \mathrm{E}-04$ \\
166 & 92 & 1.35 & $6.70 \mathrm{E}-03$ & 1.09 & 0.0182 & $1.62 \mathrm{E}-04$ \\
193 & 105 & 1.39 & $5.80 \mathrm{E}-03$ & 1.00 & 0.0197 & $1.62 \mathrm{E}-04$ \\
213 & 115 & 1.41 & $5.30 \mathrm{E}-03$ & 0.96 & 0.0208 & $1.62 \mathrm{E}-04$ \\
219 & 118 & 1.42 & $5.10 \mathrm{E}-03$ & 0.94 & 0.0211 & $1.62 \mathrm{E}-04$ \\
230 & 122 & 1.43 & $4.90 \mathrm{E}-03$ & 0.91 & 0.0217 & $1.62 \mathrm{E}-04$ \\
248 & 131 & 1.45 & $4.50 \mathrm{E}-03$ & 0.85 & 0.0227 & $1.62 \mathrm{E}-04$ \\
283 & 147 & 1.50 & $4.00 \mathrm{E}-03$ & 0.75 & 0.0246 & $1.62 \mathrm{E}-04$ \\
317 & 163 & 1.54 & $3.50 \mathrm{E}-03$ & 0.65 & 0.0265 & $1.62 \mathrm{E}-04$ \\
353 & 180 & 1.58 & $3.20 \mathrm{E}-03$ & 0.54 & 0.0285 & $1.62 \mathrm{E}-04$ \\
360 & 183 & 1.59 & $3.10 \mathrm{E}-03$ & 0.52 & 0.0289 & $1.62 \mathrm{E}-04$ \\
\hline
\end{tabular}

Table 5. Economic parameters (Gaspar et al., 2015).

\begin{tabular}{|c|c|c|}
\hline \multirow{3}{*}{ Market Values } & Discount Rate (\%) & 9 \\
\hline & Oil Price (USD/bbl) & 50 \\
\hline & Special Taxes on G. Revenue (\%) & 9.25 \\
\hline \multirow{3}{*}{ Taxes } & Corporate Taxes (\%) & 34 \\
\hline & Royalties (\%) & 10 \\
\hline & Oil Production (USD/bbl) & 10 \\
\hline \multirow[t]{3}{*}{ Costs } & Water Production (USD/bbl) & 1 \\
\hline & Water Injection (USD/bbl) & 1 \\
\hline & Horizontal Well $\left(10^{3} \mathrm{USD} / \mathrm{m}\right)$ & 61.17 \\
\hline Investments & Additional Vertical Well ( $10^{3}$ USD) & 21.67 \\
\hline
\end{tabular}

Figure 7 shows the variation in NPV (the difference for the strategies before and after the optimization $-\Delta \mathrm{NPV}$ ). Note that, although all strategies in the RM-c present positive NPV variation, some strategies present negative variation in the reference case. Furthermore, all strategies presenting negative NPV variation in the reference case also showed this characteristic in model R-c.

The best strategy (i.e. highest economic return for the reference case) is that optimized for model R-c, which indicates that the effect of the uncertainties, in terms of $\mathrm{NPV}$, is stronger than the effect of upscaling. In fact, we can see in Figure 8a the strong correlation between the NPV of the strategies applied to the reference case and the NPV of strategies applied to model R-c. In Figure 8b, the

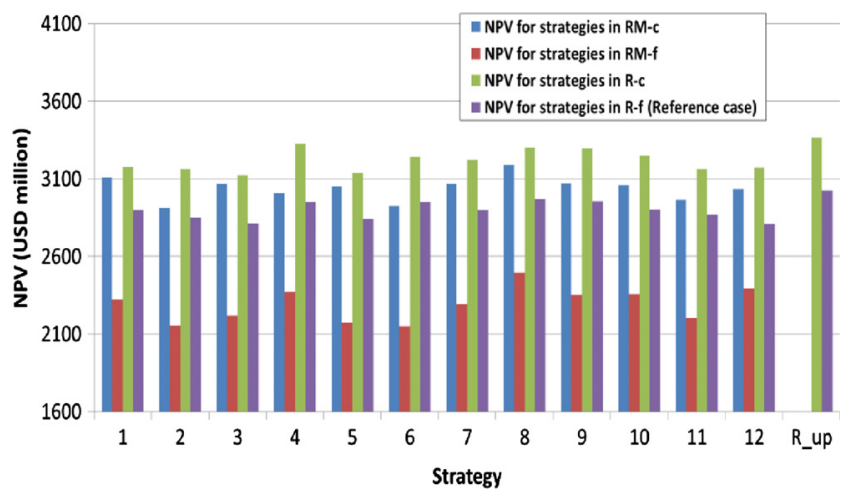

Fig. 5. NPV obtained for all 13 strategies, applied to RM-c (blue columns), RM-f (red columns), R-c (green columns), and R-f (purple columns).

NPV of the reference case and the representative models noticeably do not correlate. In Figure 8c, we also see no correlation between the NPV of the reference case and the NPV of RM-f models.

Figure 9 shows how the correlation changes regarding cumulative oil production for the strategies simulated for the reference case $\left(\mathrm{Np}_{\mathrm{R}-\mathrm{f}}\right)$ against model $\mathrm{R}-\mathrm{c}\left(\mathrm{Np}_{\mathrm{R}-\mathrm{c}}\right)$ in Figure $9 \mathrm{a}$; against the representative models $\left(\mathrm{Np}_{\mathrm{RM}-\mathrm{c}}\right)$ in Figure $9 \mathrm{~b}$; and against models RM-f ( $\left.\mathrm{Np}_{\mathrm{RM}-\mathrm{f}}\right)$ in Figure 9c. Analyzing the result graphs, we observe that the first case presents better correlation than the second and third, similarly to the analysis for NPV. 


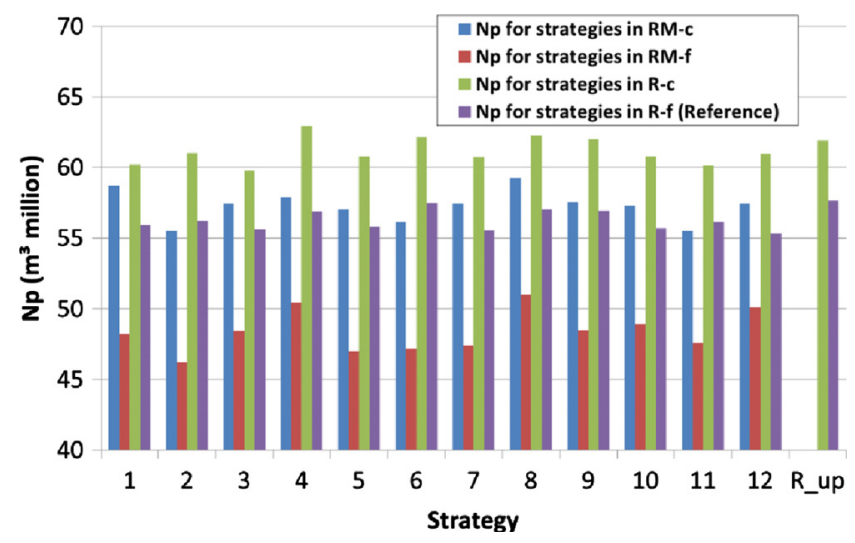

Fig. 6. Cumulative oil produced for all the 13 strategies, applied to RM-c (blue columns), RM-f (red columns), R-c (green columns), and R-f (purple columns).

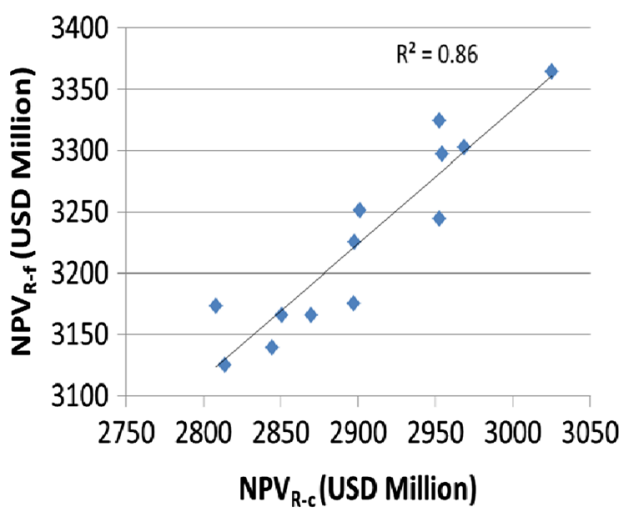

(a)

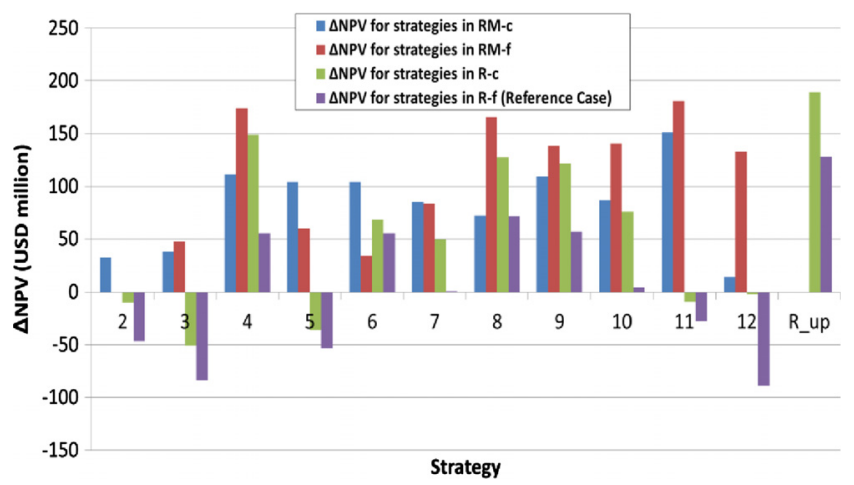

Fig. 7. Variation in NPV for all the 13 strategies, applied to RMc (blue columns), RM-f (red columns), R-c (green columns), and R-f (purple columns).

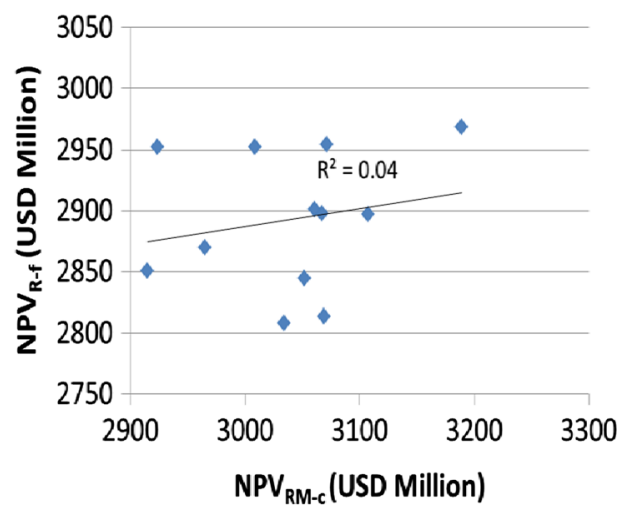

(b)

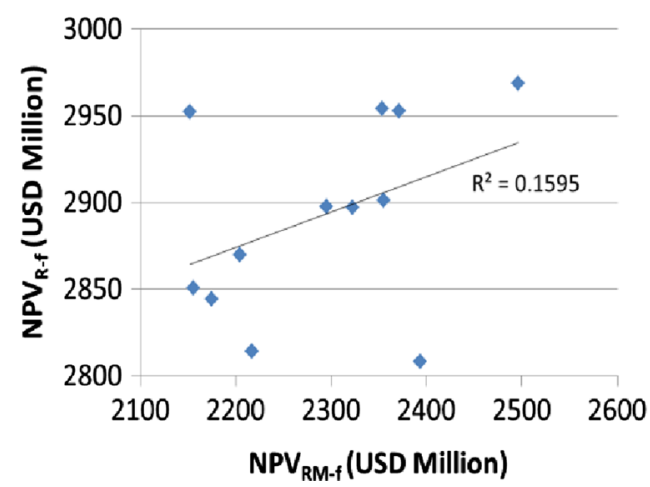

(c)

Fig. 8. Relationship between a) $N P V_{R-c} \times N P V_{R-f}$; b) $N P V_{R M-c} \times N P V_{R-f}$; and c) $N P V_{R M-f} x N_{R-f}$.

In addition to the cross-plot analysis, it is important to show and compare the production curves for all cases. Figure 10 shows the oil production over time for selected wells with different strategies simulated in different models. In these graphs, brown lines represent the reference case, blue lines are RM-c, green lines are R-c, and red lines refer to RM-f. After comparing all production curves, the curve in model R-c is the closest to the real response. Moreover, the representative models are clearly more affected by uncertainty than upscaling. Note that these wells were implemented after the optimization process and did not go through a history-matching process.

These results show that the production forecasts, for this case, were greatly impacted by uncertainties. Since the response of the wells greatly depends on the petrophysical properties of the model, they can vary considerably between the different models representing the uncertainties. Even when well history matched, the models may 


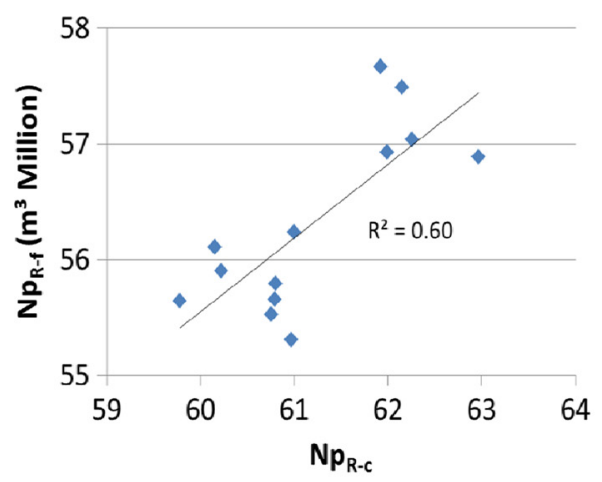

(a)

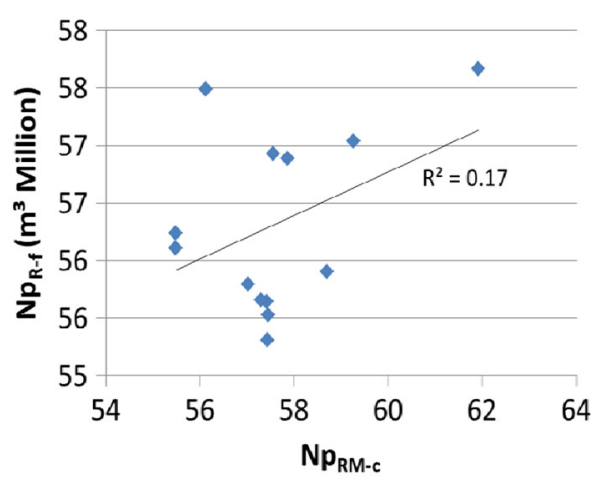

(b)

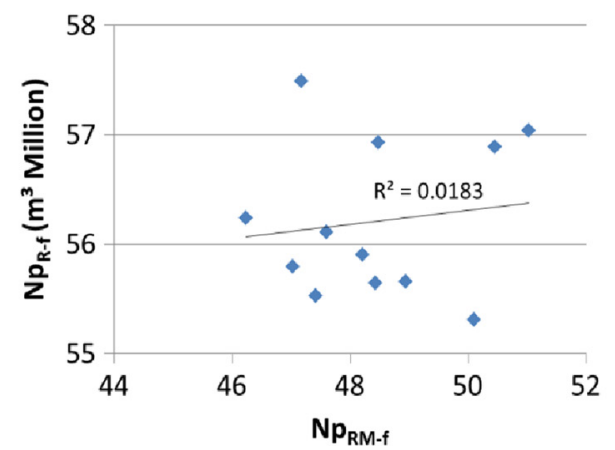

(c)

Fig. 9. Relationship between a) $\mathrm{Np}_{\mathrm{R}-\mathrm{c}} \mathrm{x} \mathrm{Np}_{\mathrm{R}-\mathrm{f}}$; b) $\mathrm{Np}_{\mathrm{RM}-\mathrm{c}} \mathrm{x} \mathrm{Np}_{\mathrm{R}-\mathrm{f}}$; and (c) $\mathrm{Np}_{\mathrm{RM}-\mathrm{f}} \mathrm{x} \mathrm{Np}_{\mathrm{R}-\mathrm{f}}$.

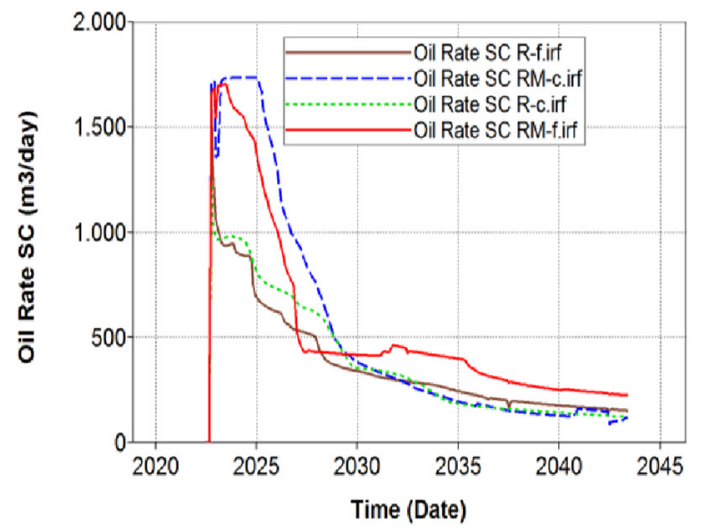

(a)

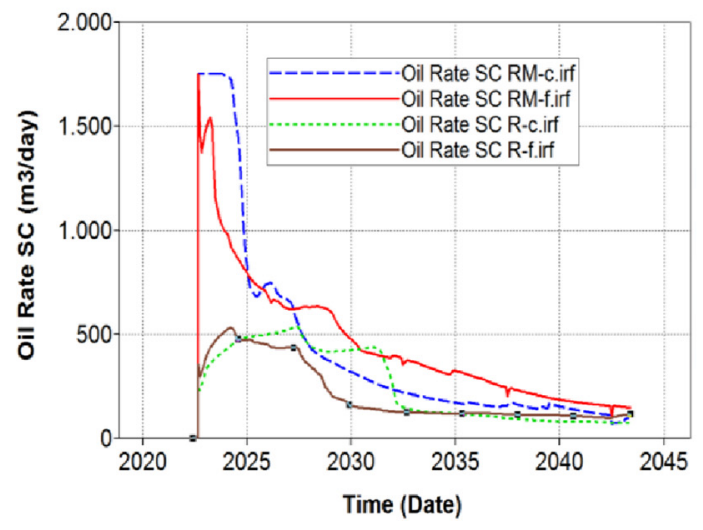

(c)

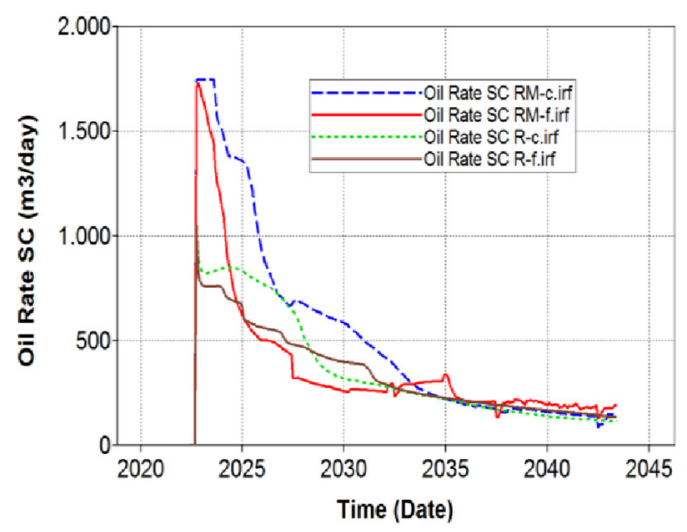

(b)

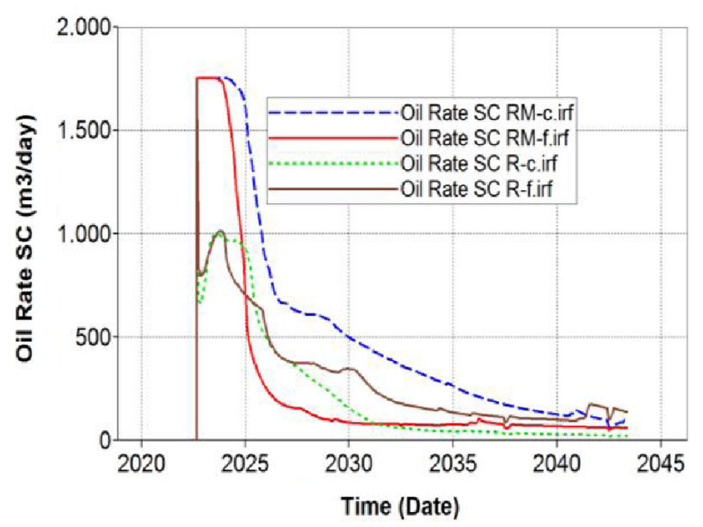

(d)

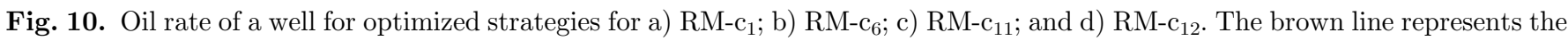
reference case, the blue line is RM-c, the green line is R-c, and red line refers to RM-f. 


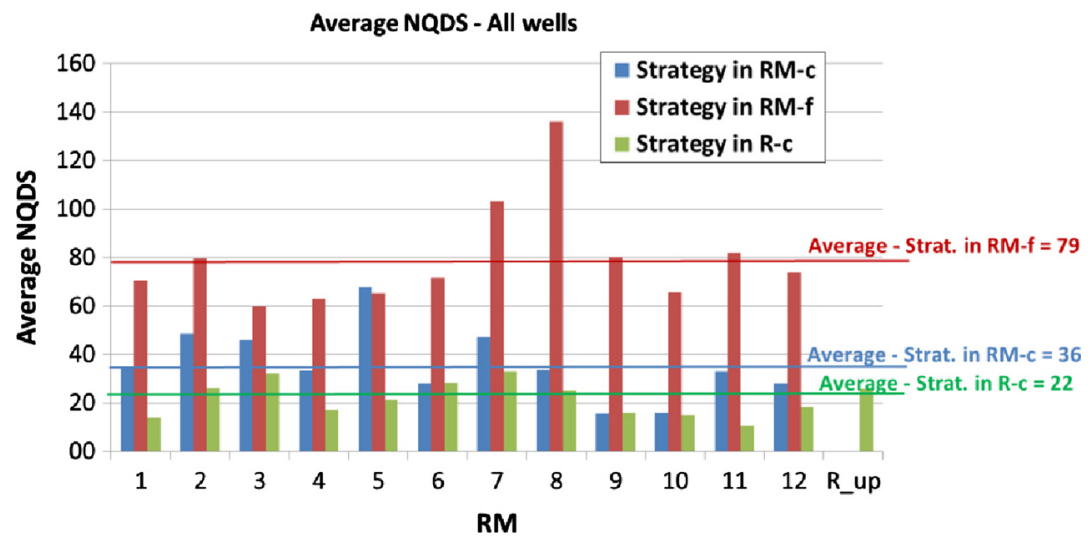

Fig. 11. Average absolute NQDS of all strategies.

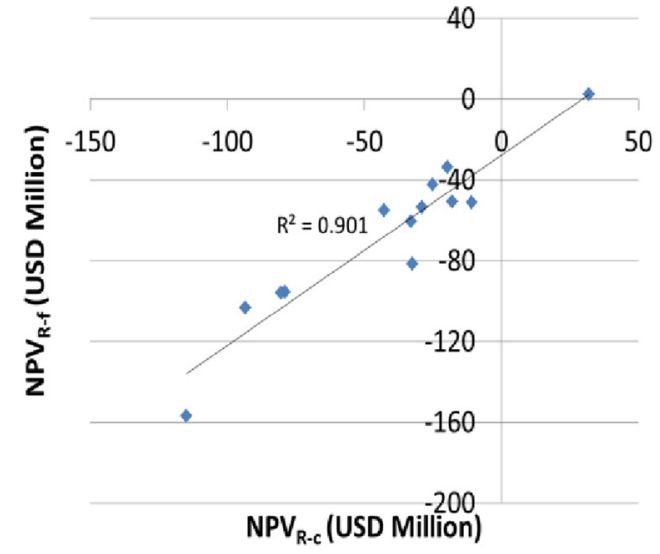

(a)

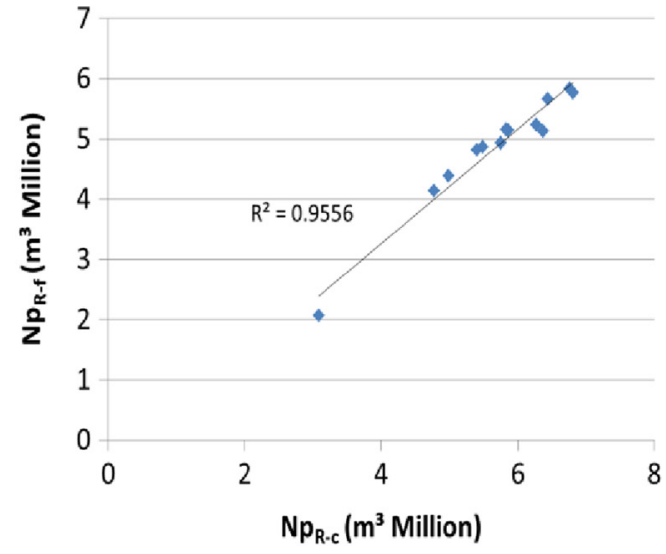

(b)

Fig. 12. Relationship between a) $\mathrm{NPV}_{\mathrm{R}-\mathrm{c}} \mathrm{x} \mathrm{NPV}_{\mathrm{R}-\mathrm{f}}$ and b) $\mathrm{Np}_{\mathrm{RM}-\mathrm{c}} \mathrm{x} \mathrm{Np}_{\mathrm{R}-\mathrm{f}}$ and, considering oil viscosity of $100 \mathrm{cP}$.

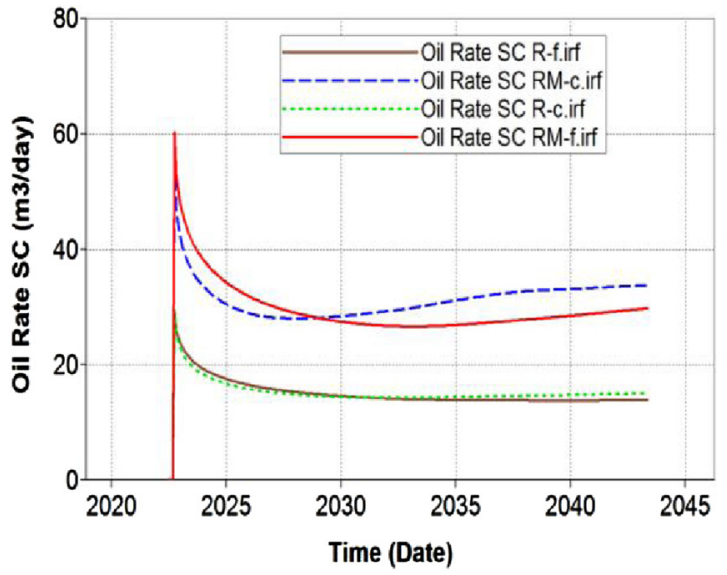

(a)

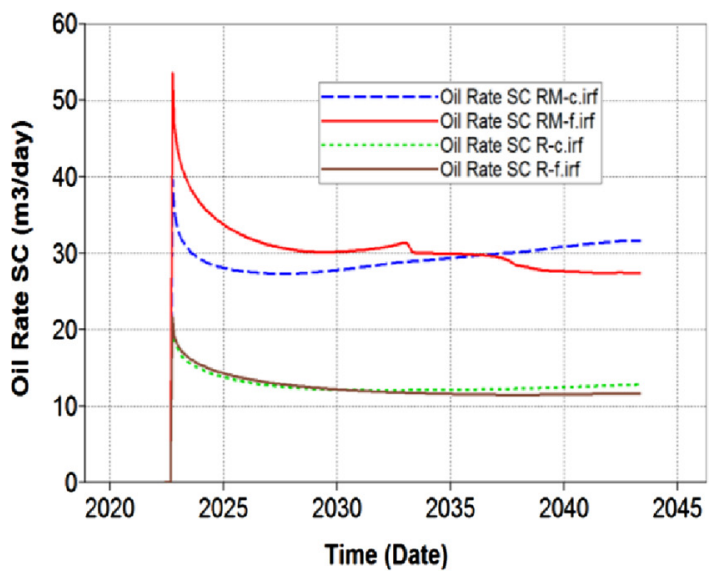

(b)

Fig. 13. Oil rate of a well for optimized strategies for a) RM-c $c_{1}$ and $b$ ) $R M-c_{6}$, considering oil viscosity of $100 \mathrm{cP}$. The brown line represents the reference case, the blue line is RM-c, the green line is R-c, and red line refers to RM-f.

present areas that are considerably different to the real field, causing potential errors in production forecasts and in model-based decisions.

The figures above are examples of qualitative analysis of some production curves for wells applied to different models. To better quantify the difference between curves, a useful indicator is the Normalized Quadratic Distance with Signal (NQDS) (Almeida et al., 2017; Avansi et al., 2016; Maschio and Schiozer, 2016), shown in Equation (1). 


$$
\mathrm{NQDS}=\frac{S D}{|S D|} * \frac{\sum_{n}^{i=1}\left(\operatorname{Sim}_{i}-\mathrm{Hist}_{i}\right)^{2}}{\sum_{n}^{i=1}\left(\mathrm{Hist}_{i} * \text { tol }+C_{p}\right)^{2}},
$$

where " $\hat{\imath}$ " corresponds to an index of time; "Sim" the value of simulated data and "Hist" the value of historical data; "tol" is a tolerance given by a percentage of the observed data; " $C_{p}$ " is a constant to prevent division by zero in the formula; and "SD" is the simple deviation (Eq. 2).

$$
\mathrm{SD}=\sum_{i=1}^{n}\left(\operatorname{Sim}_{i}-\text { Hist }_{i}\right)
$$

The closer to zero NQDS is, the closer the two curves being compared are. NQDS equals to zero means the curves are coincident.

We calculated the average of absolute NQDS of the following well parameters for all strategies: oil and water rates, cumulative oil, and water production. The parameter values of UNISIM-I-R were used as reference for NQDS calculation. Figure 11 shows that the lowest average NQDS was obtained for strategies simulated in model R-c, demonstrating again that the results obtained in this model are the closest to the reference case.

It is highlighted that the simulation models went through a history-matching process, and these results demonstrate that this does not guarantee models to be representative of the field. This is important mainly when defining new wells for the strategy, since the regions of the model without wells may be poorly represented. Using seismic data is one possible way to improve the quality of the models for history matching (Davolio et al., 2013; Assunção et al., 2016; Almeida et al., 2017).

\section{Effects of higher oil viscosity}

The oil viscosity presented in this study is similar to that of the water, hence coupling effects are not expected to occur. However, as mentioned in the Introduction, the strong interaction between the heterogeneity and an unstable character of the fluid flow displacement can affect the upscaling. Thus, we performed the simulation runs changing the oil viscosity to a value a hundred times higher than the original case $(\sim 100 \mathrm{cP})$, hence a more unstable flow is expected, and we wish to analyze how this impacts the upscaling.

Figure 12 shows that the strong correlation between the indicators (NPV for Fig. 12a and Np for Fig. 12b) of the strategies applied to the reference case and the indicators of strategies applied to model R-c is maintained, even with oil viscosity much higher than water viscosity.

Figure 13 shows the oil production over time for selected wells with different strategies simulated in different models. Similarly to the behavior shown in Figure 10, the curve in the model R-c is the closest to the reference case (R-f). Thus, even with very different viscosities between oil and water, the RM were more affected by uncertainty than upscaling, which is an indicative that coupling effects are not the main issue in this study case.

\section{Conclusion}

To understand the causes of biases presented by production forecasts of simulation models, our analysis focused on two sources of errors: uncertainties and upscaling. We used a reference case as the real response and a set of simulation models to include both effects. Moreover, we used a simulation model derived from the reference case to exclude the effects of the uncertainties, as well as a set of fine-scale models to exclude the effects of the upscaling.

The results showed that, for the studied case, the uncertainties have a stronger impact on production and economic indicators than the upscaling. The upscaling generates an optimistic bias towards production and economic indicators, but they are well correlated with the real response. The production forecasts were greatly impacted by uncertainties because the response of the wells is highly dependent on the petrophysical properties of the model, which can vary a lot between the different models characterizing the uncertainties and were poorly represented in the representative models.

\section{Nomenclature}

$\mathrm{Bg} \quad$ Gas formation volume factor

Bo Oil formation volume factor

Cp Constant to prevent division by zero

Hist ${ }_{i} \quad$ Historical data in time ' $i$ '

Kro Oil relative permeability

Krw Water relative permeability

$\mathrm{Np} \quad$ Cumulative oil produced

$\mathrm{Np}_{\mathrm{R}-\mathrm{c}} \quad$ Cumulative oil produced of the strategies simulated in model R-c

$\mathrm{Np}_{\mathrm{R}-\mathrm{f}} \quad$ Cumulative oil produced of the strategies simulated in the reference case

$\mathrm{Np}_{\mathrm{RM}-\mathrm{c}} \quad$ Cumulative oil produced of the strategies simulated in the representative models

$\mathrm{Np}_{\mathrm{RM}-\mathrm{f}} \quad$ Cumulative oil produced of the strategies simulated in RM-f

NPV Net Present Value

$\mathrm{NPV}_{\mathrm{R}-\mathrm{c}} \quad$ Net Present Value of the strategies simulated in model R-c

$\mathrm{NPV}_{\mathrm{R}-\mathrm{f}} \quad$ Net Present Value of the strategies simulated in the reference case

NPV $V_{\text {RM-c }}$ Net Present Value of the strategies simulated in the representative models

NPV $_{\text {RM-f }}$ Net Present Value of the strategies simulated in RM-f

NQDS Normalized Quadratic Distance with Signal

p Pressure

R-c Reference case (fine-scale grid)

$\mathrm{R}-\mathrm{f} \quad$ Upscaling in reference case (coarse grid)

RM-c Representative Models in coarse scale

RM-f Representative Models in fine scale

Rs Gas solubility

SD Simple Deviation

$\mathrm{Sim}_{\mathrm{i}} \quad$ Simulation value in time ' $i$ '

tol Tolerance 
Acknowledgments. This work was carried out in association with the Project registered as BG-07 "Reduction of uncertainties through the incorporation of 4D seismic data in the modeling of the reservoir" (UNICAMP/Shell Brazil/ANP) funded by Shell Brazil under the ANP R\&D levy as "Investment Commitment to Research and Development". The authors also would like to thank CMG for software licenses.

\section{References}

Al-Harthy M.H. (2010) Number of development wells: A decision under Uncertainty, Eng. Econ. 55, 4, 328-349. DOI:10.1080/ 0013791X.2010.524281

Almeida F.L., Davolio A., Schiozer D.J. (2017) Methodology to systematically reduce uncertainty assimilating quantitatively $4 \mathrm{D}$ seismic and well data in a probabilistic and multi-objective history matching, SPE 187081, in: SPE Annual Technical Conference and Exhibition, San Antonio, Texas, USA. DOI:10.2118/187081-MS

Ani M., Oluyemi G., Petrovski A., Rezaei-Gomari S. (2016) Reservoir uncertainty analysis: The trends from probability to algorithms and machine learning, SPE 181049, in: SPE Intelligent Energy International Conference and Exhibition, Aberdeen, United Kingdom. DOI:10.2118/181049-MS

Artus V., Noetinger B. (2004) Up-scaling two-phase flow in heterogeneuos reservoirs: Current trends, Oil Gas Sci. Technol. 59, 2, 185-195. DOI:10.2516/ogst:2004014

Assunção G.S.C., Davolio A., Schiozer D.J. (2016) A methodology to integrate multiple simulation models and 4D seismic considering their uncertainties, SPE 181608-MS, in: Annual Technical Conference and Exhibition, Dubai, UAE. DOI:10.2118/181608-MS

Avansi G.D., Schiozer D.J. (2015) UNISIM-I: Synthetic model for reservoir development and management applications, Int. J. Model. Simul. Pet. Ind. 9, 1, 21-30

Avansi G.D., Maschio C., Schiozer D.J. (2016) Simultaneous history-matching approach by use of reservoir-characterization and reservoir-simulation studies, SPE Reserv. Eval. Eng. 19, 4, 694-712. DOI:10.2118/179740-PA

Begg S., Bratvold R. (2008) Systematic prediction errors in O\&G project and portfolio selection, SPE 116525-MS, in: Annual Technical Conference and Exhibition, Denver, Colorado, USA. DOI:10.2118/116525-MS

Begg S., Bratvold R., Campbell J. (2002) The value of flexibility in managing uncertainty in oil and gas investments, SPE 77586-MS, in: Annual Technical Conference and Exhibition, San Antonio, Texas, USA. DOI:10.2118/77586-MS

Bickel J.E., Bratvold R.B. (2008) From uncertainty quantification to decision making in the oil and gas industry, Energy Explor. Exploit. 26, 5, 311-325. DOI:10.1260/ 014459808787945344

Bordeaux-Rego F., Botechia V.E., Correia M.G., Schiozer D.J. (2016) Quantifying the impact of grid size to compare water and polymer flooding strategies in a highly heterogeneous offshore field, Braz. J. Pet. Gas 10, 2, 63-76. DOI:10.5419/bjpg2016-0006

Bratvold R.B., Bickel J.E., Lohne H.P. (2009) Value of information in the oil and gas industry: Past, present and future, SPE 110378-PA, SPE Reserv. Eval. Eng. 12, 4, 630638. DOI: $10.2118 / 110378-\mathrm{PA}$

Chen M., Dyer J. (2009) Inevitable disappointment in projects selected on the basis of forecasts, SPE 107710-PA, SPE J. 14, 2 , 216-221. DOI:10.2118/107710-PA
Coopersmith E.M., Cunningham P.C. (2002) A practical approach to evaluating the value of information and real option decisions in the upstream petroleum industry, SPE 77582-MS, in: Annual Technical Conference and Exhibition, San Antonio, Texas, USA. DOI:10.2118/77582-MS

Costa A.P.A., Schiozer D.J., Moczydlower P., Bedrikovetsky P. (2008) Use of representative models to improve the decision making process of chemical flooding in a mature field, SPE 115442, in: SPE Russian Oil and Gas Technical Conference and Exhibition, Moscow, Russia. DOI:10.2118/115442-MS

Cunha J.C. (2007) Recent developments on application of decision analysis for the oil industry, SPE 108703, in: 2007 International Oil Conference and Exhibition in Mexico, Veracruz, Mexico. DOI:10.2118/108703-MS

Davolio A., Maschio C., Schiozer D.J. (2013) Local history matching using 4D seismic data and multiple models combination, SPE 164883, in: EAGE Annual Conference and Exhibition incorporating Europec, London, United Kingdom. DOI:10.2118/164883-MS

Deutsch C. (1989) Calculating effective absolute permeability in sandstone/shale sequences, SPE 17264-PA, SPE Form. Eval. 4, 3, 343-348. DOI:10.2118/17264-PA

Dubrule O. (1998) Geostatistics in petroleum geology, AAPG Continuing Education Course Note Series \#38, The American Association of Petroleum Geologists, Tulsa, Oklahoma, USA

Fletcher A., Davis J.P. (2002) Decision-making with incomplete evidence, SPE 77914, in: SPE Asia Pacific Oil and Gas Conference and Exhibition, Melbourne, Australia. DOI:10.2118/77914-MS

Gaspar A.T.F.S., Avansi G.D., Santos A.A.S., Hohendorff F.J.C. V., Schiozer D.J. (2015) Unisim-I-D: Benchmark studies for oil field development and production strategy selection, Int. J. Model. Simul. Pet. Ind. 9, 1, 47-55

Gaspar A.T.F.S., Barreto C.E.A., Mazo E.O.M., Schiozer D.J. (2016a) Assisted process for design optimization of oil exploitation strategy, J. Petrol. Sci. Eng. 146, 473-488

Gaspar A.T.F.S., Avansi G.D., Maschio C., Santos A.A.S., Schiozer D.J. (2016b) Unisim-I-M: Benchmark case proposal for oil reservoir management decision-making, SPE 180848, in: SPE Energy Resources Conference, Port of Spain, Trinidad and Tobago. DOI:10.2118/180848-MS

Gerhardt J.H., Haldorsen H.H. (1989) On the value of information, SPE 19291-MS, in: Offshore Europe, Aberdeen, United Kingdom. DOI:10.2118/19291-MS

Gorell S., Bassett R. (2001) Trends in reservoir simulation: Big models, scalable models? Will you please make up your mind? in: SPE Annual Technical Conference and Exhibition, New Orleans, Los Angeles, USA. DOI:10.2118/71596-MS

Harrison J.R., March J.G. (1984) Decision making and postdecision surprises, Admin. Sci. Q. 29, 26-42. DOI: $10.2307 / 2393078$

Keisler J.M., Zachary A.C., Chu E., Sinatra N., Linkov I. (2014) Value of information analysis: The state of application, Environ. Syst. Dec. 34, 1, 3-23. DOI:10.1007/s10669-013-9439-4

Kelkar M., Perez G. (2002) Applied Geostatistics for Reservoir Characterization, Society of Petroleum Engineers Inc., Richardson, Texas, USA

Korounis D., Durlofsky L.J., Jansen J.D., Aziz K. (2014) Adjoint formulation and constraint handling for gradient-based optimization of compositional reservoir flow, Comput. Geosci. 18, 2, 117-137. DOI:10.1007/s10596-013-9385-8

Luo H., Mohanty K.K., Delshad M., Pope G.A. (2016) Modeling and upscaling unstable water and polymer floods: Dynamic 
characterization of the effective finger zone, SPE 179648, in: SPE Improved Oil Recovery Conference, Tulsa, USA. DOI:10.2118/179648-MS

Marques M.D., Gaspar A.T., Schiozer D.J. (2013) Use of oil reservoir simulation to estimate value of flexibility, SPE 164878, in: EAGE Annual Conference and Exhibition incorporating Europec, London, United Kingdom. DOI:10.2118/ 164878-MS

Maschio C., Schiozer D.J. (2003) A new upscaling technique based on dykstra-parsons coefficient: Evaluation with streamline reservoir simulation, J. Petrol. Sci. Eng. 40, 27-36. DOI:10.1016/S0920-4105(03)00060-3

Maschio C., Schiozer, D.J. (2016) Probabilistic history matching using discrete latin hypercube sampling and nonparametric density estimation, J. Petrol. Sci. Eng. 147, 98-115. DOI:10.1016/j.petrol.2016.05.011

Meira L.A.A., Coelho G.P., Santos A.A.S., Schiozer D.J. (2016) Selection of representative models for decision analysis under uncertainty, Comput. Geosci. 88, 67-82. DOI:10.1016/j. cageo.2015.11.012

Morosov L., Schiozer D.J. (2016) Field development process revealing uncertainty assessment pitfalls, SPE 180094, in: SPE Europec, Vienna, Austria. DOI:10.2118/180094-MS

Noetinger B., Artus V., Ricard L. (2004) Dynamics of the wateroil front for two-phase, Immiscible flow in heterogeneous porous media, 2-isotropic media, Transp. porous media $\mathbf{5 6}, 3$, 305-328

Noetinger B., Artus V., Zargar G. (2005) The future of stochastic and upscaling methods in hydrogeology, Hydrogeol. J. 13, 1, 184-201. DOI:10.1007/s10040-004-0427-0

Oliveira D.F.B., Reynolds A.C., Jansen J.D. (2015) An improved multiscale method for life-cycle production optimization, Comput. Geosci. 19, 6, 1139-1157. DOI:10.1007/s10596-015-9530-7

Pattillo P.D., Payne M.L., Webb T.R., Sharadin J.H. (2003) Application of decision analysis to a deepwater well integrity assessment, OTC 15133, in: Offshore Technology Conference, Houston, USA. DOI:10.4043/15133-MS

Preux C. (2014) About the use of quality indicators to reduce information loss when performing upscaling, Oil Gas Sci. Technol. 71, 7. DOI:10.2516/ogst/2014023

Preux C., Le Ravalec M., Enchéry G. (2016) Selecting an appropriate upscaled reservoir model based on connectivity analysis, Oil Gas Sci. Technol. 71,60. DOI:10.2516/ogst/2016015
Ravenne C., Galli A., Doligez B., Beucher H., Eschard R. (2002) Quantification of facies relationships via proportion curves, in: Geostatistics Rio 2000: Proceedings of the Geostatistics Sessions of the 31st International Geological Congress, Rio de Janeiro. DOI:10.1007/978-94-017-1701-4

Romeu R.K., Noetinger B. (1995) Calculation of internodal transmissivities in finite difference models of flow in heterogeneous porous media, Water Resour. Res. 31, 4, 943-959

Santos S.M.G., Gaspar A.T.F.S., Schiozer D.J. (2017) Value of information in reservoir development projects: Technical indicators to prioritize uncertainties and information sources, J. Petrol. Sci. Eng. 157, 1179-1191. DOI:10.1016/j.petrol.2017.08.028

Sarma P., Chen W.H., Xie J. (2013) Selecting representative models from a large set of models, SPE 163671, in: SPE Reservoir Simulation Symposium, The Woodlands, Texas, USA. DOI:10.2118/163671-MS

Schiozer D.J., Ligero E.L., Suslick S.B., Costa A.P.A., Santos J. A.M. (2004) Use of representative models in the integration of risk analysis and production strategy definition, J. Petrol. Sci. Eng. 44, 1, 131-141. DOI:10.1016/j.petrol.2004.02.010

Schiozer D.J., Santos A.A.S., Drumond P.S. (2015) Integrated model based decision analysis in twelve steps applied to petroleum fields development and management, SPE 174370, in: Europec 2015, Madrid, Spain. DOI:10.2118/174370-MS

Schiozer D.J., Avansi G.D., Santos A.A.S. (2017) Risk quantification combining geostatistical realizations and discretized latin hypercube, J. Braz. Soc. Mech. Sci. Eng. 39, 2, $575-587$

Schuyler J., Nieman T. (2007) Optimizer's curse: Removing the effect of this bias in portfolio planning, SPE 107852, in: SPE Hydrocarbon Economics and Evaluation Symposium, Dallas, Texas, USA. DOI:10.2118/107852-MS

Seifert D., Jensen J.L. (1999) Using sequential indicator simulation as a tool in reservoir description: Issues and uncertainties, Math. Geol. 31, 5, 527-550. DOI:10.1023/ a:1007563907124

Shirangi M.G., Durlofsky L.J. (2015) Closed-Loop field development under uncertainty by use of optimization with sample validation, SPE 173219-PA, SPE J. 20, 5, 908-922. DOI: $10.2118 / 173219-\mathrm{PA}$

Smith J.E., Winkler R.L. (2006) The optimizer's curse: Skepticism and postdecision surprise in decision analysis, Manag. Sci. 52, 3, 311-322. DOI:10.1287/mnsc.1050.0451 